\title{
Polyphenols composition of wine and grape sub-products and potential effects on chronic diseases
}

\author{
Isabelle $\mathrm{Ky}^{\mathrm{a}, \mathrm{b}}$, Alan Crozier ${ }^{\mathrm{b}}$, Gérard $\operatorname{Cros}^{\mathrm{c}}$ and Pierre-louis Teissedre ${ }^{\mathrm{a}, *}$ \\ ${ }^{a}$ Université Bordeaux Segalen, Institut des Sciences de la Vigne et du Vin, Villenave d'Ornon Cedex, France \\ ${ }^{\mathrm{b}}$ School of Medicine, Joseph Black Building, North Laboratory, College of Medical, Veterinary and Life Sciences, \\ University of Glasgow, Glasgow, UK \\ ${ }^{\mathrm{c}}$ Laboratoire de Pharmacologie et Physiopathologies Expérimentales, Centre de Pharmacologie et d'Innovation \\ dans le Diabète, Faculté de Pharmacie, Montpellier-Cedex, France
}

\begin{abstract}
Grape (Vitis vinifera) is one of the most cultivated fruit crops in the world, with an approximate annual production of $\sim 64$ million metric tons in 2010 (OIV, 2011). Grapes composition in polyphenols and their extractability which is far from complete and typically reaching only $30-40 \%$ depend on grape varieties, vineyard location and the technological parameters during wine making process including destemming, crushing, maceration and pressing. Therefore, grape pomace potentially constitutes a very abundant and relatively inexpensive source of a wide range of polyphenols including monomeric and oligomeric flavan3-ols (proanthocyanidins) as well as anthocyanins (glucosides, acetylated glucosides and coumarylic glucosides). Moreover, it has been evaluated as a potential source of antioxidant polyphenols which could be used as nutraceuticals or food additives. Actually, phenolic compounds are known to have some health benefits such as a chemopreventive role toward cardiovascular, cancer, and degenerative diseases.

In order to valorize wine by-products from Rhone Valley area, grape and pomace seeds and skins from red wine cultivars at maturity from the vintage 2009 and 2010 (Grenache, Syrah, Carignan, Mourvédre, Counoise and Alicante) have been characterised for their phenolic contents (total phenol contents, tannin and anthocyanin contents - total and individuals; quantification of monomeric and oligomeric proanthocyanidins as well as some anthocyanins (glucosides, acetylated glucosides and coumarylic glucosides)). Ratio of initial phenolic compounds from grape to pomace was also estimated.

The comparison of several wine industry by-products with their respective grapes provided evidence that grape seed and skin pomace extracts still contained appreciable amounts of flavanol-3-ols and anthocyanins even after the fermentation process. Quantitative and qualitative distribution of polyphenols in grape pomaces showed significant differences through varieties. Seed extracts from grapes and pomaces contain exceptionally high amounts of total polyphenols than skin's extracts. This study evidenced seeds from Grenache, Syrah and Alicante and skins from Syrah, Carignan and Alicante as the most interesting fractions to be valorized because of their richest contents in polyphenols compared to the other assessed fractions and varieties. This work further supports that grape pomaces obtained after vinification still retained a significant amount of polyphenols of which level depends largely on the vintage. The use of this by-product would constitute a promising natural source of available polyphenols which could be included in nutraceutical formulation. Activity effects of grape by-products on a chronic disease model with hypertension are given.
\end{abstract}

\section{Introduction}

${ }^{*}$ Corresponding author: Pierre-louis Teissedre, Université Bordeaux Segalen, Institut des Sciences de la Vigne et du Vin, EA 4577USC Oenologie 1366 INRA-UBS-IPB, 210, chemin de Leysotte, CS 50008, 33882 Villenave d'Ornon Cedex, France. E-mail: p.teissedre@u-bordeaux2.fr.

Hypertension is the most important of cardiovascular risk factor worldwide. According to the World Health Organization 2013 data, hypertension accounted for approximately 9.4 million deaths a year, 
contributing to $45 \%$ of deaths due to heart disease and $51 \%$ of deaths due to stroke. The prevalence of hypertensive people is low under 25 years old but steadily increases to attend $40 \%$ at 65 years old and $90 \%$ at 85 years old. It is estimated that by 2030 , more than 23 million people will die annually from cardiovascular diseases (CVDs). The importance of oxidative stress, vascular inflammation and endothelial dysfunction has to be highlighted in the development of CVDs. The knowledge of the process has provided new perspectives to elaborate novel pharmaceutical or dietary strategies to control the development of vascular diseases.

Epidemiological studies have shown an inverse correlation between the consumption of polyphenols enriched diet and reduced risks of CVDs [1-3]. The potential mechanisms of preventing CVDs could be related to the antioxidant activity conferred by polyphenols involving different processes and also different compounds. Indeed, more than 8000 phenolic structures can be found. Originating from the shikimic pathway and sharing at least one aromatic ring structure with one or more hydroxyl groups, a large number of polyphenol classes exist. Flavonoids are the major constituents with more than 4000 compounds. They share a common flavan core consisting of 2 aromatic rings ( $\mathrm{A}$ and $\mathrm{B}$ ) bounded by 3 carbon atoms which form an oxygenated heterocycle (ring $\mathrm{C}$ ). This class can be divided into flavanols (catechin, epicatechin), flavonols (quercetin, myricetin, kaempferol), anthocyanins (cyanidin, malvidin), flavones (apigenin), flavanones (naringenin, hesperitin) and chalcones (phloretin). The non-flavonoid group includes compounds such as stilbens (resveratrol) and phenolic acids (gallic acid) [4].

Due to the great diversity of polyphenols, the structure-activity relationship, bioavailability and therapeutic efficacy of the antioxidants differ extensively. To date, grape and wine polyphenols have showed to exert beneficial effects on health [5-7]. For instance, polyphenolic compound in grapes are known to lower oxidative stress [8], to modulate the inflammatory cascade $[9,10]$, to reduce the oxidation of LDL-c [11, 12] and to induce protection against atherothrombotic episodes including myocardial ischemia and inhibition of platelet aggregation [13, 14]. Most of these health effects have been ascribed to polyphenolic compounds serving as reducing agents in many biological systems by donating hydrogen, quenching singlet oxygen, acting as chelators and by trapping free radicals. More- over, these antioxidant activities help to limit oxidation of nucleic acids, proteins, lipids, which may initiate degenerative diseases such as cancer, heart disease, dermal disorders and aging $[15,16]$.

Moreover, polyphenols contribute to the prevention of high blood pressure and endothelial dysfunctions by preventing the NADPH oxidase vascular-dependant oxidative stress and the formation of vasoconstrictors. Polyphenols have been shown, on the one hand to increase the formation of endothelium-derived relaxing factor such as the nitric oxide (NO) [17-19], the endothelium-derived hyperpolarizing factor (EDHF) $[20,21]$ and the prostacyclin $[22,23]$ through the redox sensitive PI3-Kinase/Akt pathway and on the other hand, to inhibit the synthesis of contracting factor such as endothelin-1 [24].

A large number of publications evidenced the abundance quantity of polyphenols in grape seeds and skins, showing significant antioxidant capacity. It is therefore obvious that grape derived products such as wines, grape juices and eventually pomaces are natural sources of polyphenols. Grape pomace represents an important under used residue of the wine making process. The dry grape by-product consists of pressed skins, seeds and stems and accounts for about $20 \%$ of grapes weight used to make wine $[25,26]$. The polyphenol content of grapes and the extraction of grape polyphenols during vinification, which is far from complete, typically reaching only ca. 30-40\%, depending on grape varieties, vineyard location and technological parameters of wine making including destemming, crushing, maceration and pressing [27, 28]. Thus, grape pomace potentially constitutes a very abundant and relatively inexpensive source of a wide range of polyphenols including monomeric and oligomeric proanthocyanidins and a diversity of anthocyanin glucosides [29-33].

France is the second wine producer in the world after Italy [34] and among numerous French wine appellations, after Bordeaux, the Rhône valley is the second largest in term of surface $(73,468$ hectares) and production $(2.83$ million $\mathrm{hL})$. Vineyards in the Rhône valley grow Mediterranean grape cultivars, such as Grenache, which accounts for $65 \%$ of the planted area, as well as Syrah (15\%), Carignan (15\%) and Mourvèdre $(3 \%)$ [35]. In order to valorize wine byproducts from Rhone Valley area, grape and pomace seeds and skins from red wine cultivars at maturity from the vintage 2009 and 2010 (Grenache, Syrah, Carignan, Mourvèdre, Counoise and Alicante) 
have been characterized for their phenolic contents (total phenol contents, tannin and anthocyanin contents, monomeric and oligomeric proanthocyanidins and anthocyanins (glucosides, acetylated glucosides and coumarylic glucosides)). Ratio of initial phenolic compounds from grape to pomace was also estimated. Activity effects of grapes by-products on a chronic disease model with hypertension are given.

\section{Materials and methods}

This study was conducted in 2010 grapes at maturity and their respective grape pomaces from V.vinifera L. cv. Grenache (from two different locations [GRE1 and GRE2]), Syrah (from two different locations [SYR1 and SYR2]), Carignan (CAR), Mourvèdre (MOU), Counoise (COU) and Alicante (ALI), provided from the Rhône Valley area, appellation Châteauneufdu-Pape. Skins and seeds were removed by hand, lyophilized, grounded then extracted and separated into organic and aqueous fractions using solid-liquid extraction followed by liquid-liquid extraction.

Total polyphenol content (TPC), tannin and anthocyanin contents were determined from skin and seed extracts of grapes and pomaces by the FolinCiocalteu, the Bate-Smith and the sodium bisulfite decoloration procedures, respectively. Moreover the proanthocyanidin monomers and oligomers were identified and quantified by HPLC-UV-Fluo [36]. The anthocyanic composition (glucosides, acetyl glucosides and coumaroyl glucosides) in grape and pomace skin extracts were determined by HPLC-UV-MS.

To determine the in vivo effect of grape pomace extracts and their potential effect on hypertension, a first experiment were conducted with male 9-weekold spontaneous hypertensive rats (SHR) and their normotensive control Wistar-Kyoto (WKY) obtained from Janvier laboratory (Le Genest St. Isle, France). All rats were maintained at a constant temperature $\left(23^{\circ} \mathrm{C}\right)$, with a 12 -h dark/light cycle. Water and standard diet were given ad libitum. They were daily treated with grape pomace extract (extracted with hydroalcoholic $70 \%$ solution) by gavage during 6 weeks at a dose of $21 \mathrm{mg} / \mathrm{kg} /$ day. Rats were divided in different groups: control group (6 WKY), SHR control group (5 SHR treated with $3 \% \mathrm{EtOH}$ ) and 6 groups of 4 SHR rats treated with pomace extract dissolved in $3 \%$ EtOH (SHR1: Grenache seed pomace extract, SHR2: Syrah seed pomace extract, SHR3: Syrah skin pomace extract, SHR4: Carignan seed pomace extract, SHR5: Mourvédre skin pomace extract and SHR6: Alicante skin pomace extract). Blood pressure was measured by the tail-cuff method [37]. The average of three pressure readings was recorded for each measurement.

A second experiment was performed to study the bioavailability of three different extracts using the same experimental design. SHR rats were divided in four different groups: SHR control group (6 SHR

Table 1

Phenolic composition in grape and pomace seed extracts

\begin{tabular}{|c|c|c|c|c|c|c|}
\hline & & TPC & Total tannins & $\Sigma$ Monomers & $\Sigma$ Dimers & Trimer \\
\hline \multirow[t]{2}{*}{$\mathrm{GRE}^{\mathrm{a}}$} & Grapes & $88.71 \pm 0.99$ & $167.82 \pm 0.86$ & $2.63 \pm 0.09$ & $1.22 \pm 0.07$ & $0.23 \pm 0.04$ \\
\hline & Pomaces & $40.47 \pm 1.10$ & $83.12 \pm 0.03$ & $2.37 \pm 0.01$ & $0.67 \pm 0.05$ & $0.13 \pm 0.01$ \\
\hline \multirow[t]{2}{*}{$\mathrm{GRE}^{\mathrm{a}}{ }^{\mathrm{a}}$} & Grapes & $58.58 \pm 0.201$ & $136.84 \pm 5.22$ & $4.31 \pm 0.16$ & $1.65 \pm 0.06$ & $0.29 \pm 0.04$ \\
\hline & Pomaces & $34.94 \pm 0.21$ & $74.88 \pm 1.12$ & $3.02 \pm 0.07$ & $0.57 \pm 0.06$ & $0.11 \pm 0.02$ \\
\hline \multirow[t]{2}{*}{ SYR $1^{a}$} & Grapes & $72.84 \pm 0.694$ & $123.32 \pm 1.36$ & $7.76 \pm 0.22$ & $1.25 \pm 0.07$ & $0.29 \pm 0.01$ \\
\hline & Pomaces & $35.60 \pm 1.77$ & $79.23 \pm 1.40$ & $5.38 \pm 0.14$ & $0.26 \pm 0.02$ & $0.05 \pm 0.01$ \\
\hline \multirow[t]{2}{*}{$\mathrm{SYR}^{\mathrm{a}}$} & Grapes & $65.58 \pm 0.19$ & $115.64 \pm 1.29$ & $5.31 \pm 0.12$ & $1.10 \pm 0.09$ & $0.28 \pm 0.01$ \\
\hline & Pomaces & $33.01 \pm 1.413$ & $68.89 \pm 2.26$ & $3.01 \pm 0.08$ & $0.54 \pm 0.08$ & $0.14 \pm 0.02$ \\
\hline \multirow[t]{2}{*}{$\mathrm{CAR}^{\mathrm{a}}$} & Grapes & $58.63 \pm 3.728$ & $131.73 \pm 1.43$ & $4.63 \pm 0.52$ & $0.88 \pm 0.08$ & $0.19 \pm 0.04$ \\
\hline & Pomaces & $38.79 \pm 0.29$ & $78.7 \pm 0.21$ & $1.28 \pm 0.08$ & $0.46 \pm 0.02$ & $0.11 \pm 0.01$ \\
\hline \multirow[t]{2}{*}{$\mathrm{MOU}^{\mathrm{a}}$} & Grapes & $59.56 \pm 1.52$ & $154.91 \pm 5.24$ & $3.49 \pm 0.03$ & $0.59 \pm 0.01$ & $0.20 \pm 0.00$ \\
\hline & Pomaces & $34.52 \pm 0.11$ & $69.44 \pm 3.05$ & $0.99 \pm 0.04$ & $0.39 \pm 0.02$ & $0.10 \pm 0.01$ \\
\hline \multirow[t]{2}{*}{$\mathrm{COU}^{\mathrm{a}}$} & Grapes & $83.45 \pm 15.01$ & $143.10 \pm 21.91$ & $7.87 \pm 0.56$ & $1.37 \pm 0.05$ & $0.34 \pm 0.03$ \\
\hline & Pomaces & $40.78 \pm 3.09$ & $70.92 \pm 4.41$ & $2.84 \pm 0.09$ & $0.65 \pm 0.05$ & $0.17 \pm 0.01$ \\
\hline \multirow[t]{2}{*}{$\mathrm{ALI}^{\mathrm{a}}$} & Grapes & $76.42 \pm 8.03$ & $148.38 \pm 7.26$ & $7.36 \pm 0.29$ & $2.22 \pm 0.06$ & $0.34 \pm 0.03$ \\
\hline & Pomaces & $44.53 \pm 0.36$ & $84.92 \pm 3.97$ & $6.51 \pm 0.92$ & $1.37 \pm 0.08$ & $0.32 \pm 0.03$ \\
\hline
\end{tabular}

${ }^{\mathrm{a}} \mathrm{GRE} 1$ and GRE2, Grenache; SYR1 and SYR2, Syrah; CAR, Carignan; MOU, Mourvédre, COU, Counoise; ALI, Alicante. In units of mg/g DW seed. Data are expressed as the mean of triplicate \pm standard deviation. TPC, total phenol content; $\Sigma$ Monomers, sum of catechin and epicatechin; $\Sigma$ Dimers, sum of B1, B2, B3 and B4; Trimer, C1. 


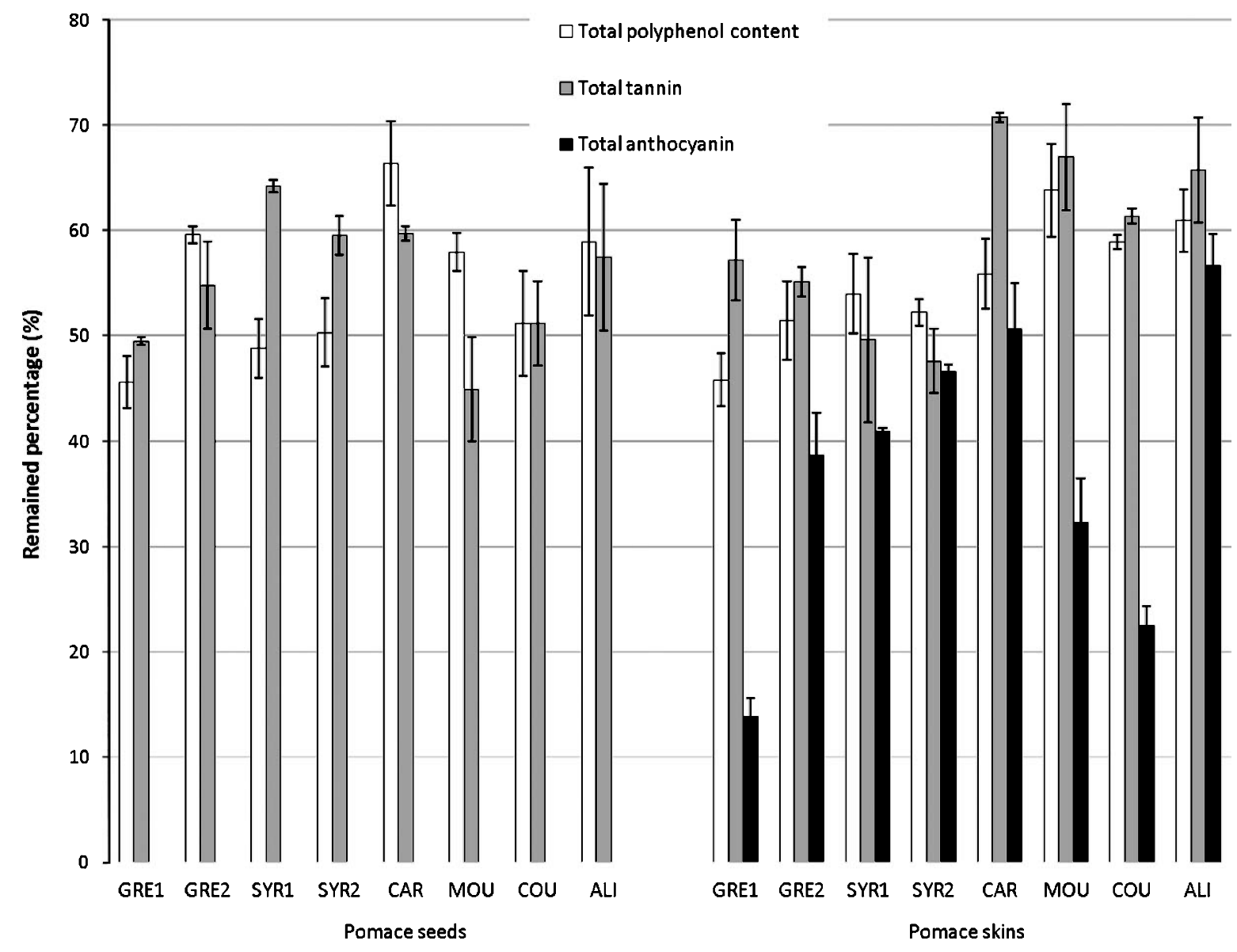

Fig. 1. Remained potential in grape pomace seed and skin extracts in 2010.

treated with $3 \% \mathrm{EtOH}$ ) and 3 groups of 6 SHR rats treated with grape pomace extract at a concentration of $21 \mathrm{mg} / \mathrm{kg} /$ day (E1: Grenache seed pomace extract, E5: Mourvédre skin pomace extract and E6: Alicante skin pomace extract). SHR were treated everyday during one week. Urines and faeces were collected at day 0 and day 7 of the experiment at two time point $(0-8 \mathrm{~h}$ and 8-24h). Urines and faeces were purified, derivatized and analysed by GC-MC for phenolic acids.

\section{Results and discussion}

\subsection{Grape pomace seeds and skins characterisation}

\subsubsection{Grape and pomace seed extracts}

Total polyphenol content was determined from skin and seed extracts of grapes and pomaces by using the Folin-Ciocalteu methodology. Generally, total polyphenol content in seed extract is higher than in skin extract for grapes and pomaces. The highest levels of TPC were founded in GRE1 and COU (88.7 and $83.4 \mathrm{mg} \mathrm{GAE} / \mathrm{g}$ DW respectively) while GRE2, MOU and CAR contained lowest amounts with an average of $59 \mathrm{mg} \mathrm{GAE} / \mathrm{g}$ DW. Total tannin levels ranged from $115.6 \mathrm{mg} / \mathrm{g}$ DW in SYR2 to $167.8 \mathrm{mg} / \mathrm{g}$ DW in GRE1. After vinification the variability was smaller ranging from 33.0 to $44.5 \mathrm{mg}$ GAE/g DW for TPC and 68.9 to $84.9 \mathrm{mg} / \mathrm{g}$ DW for total tannins (Table 1). With all the varieties, more than $45 \%$ of TCPs remained in the pomace (Fig. 1).

Concerning proanthocyanidin characterization, flavan-3-ol monomers [(+)-catechin, (-)-epicatechin] and oligomers (B1, B2, B3, B4 and the trimer C1) were identified and quantified. In grapes, $\mathrm{COU}$ contained the highest amount of monomeric and oligomeric proanthocyanidins whereas CAR and MOU had the lowest. SYR1 contained a particular rich level of 


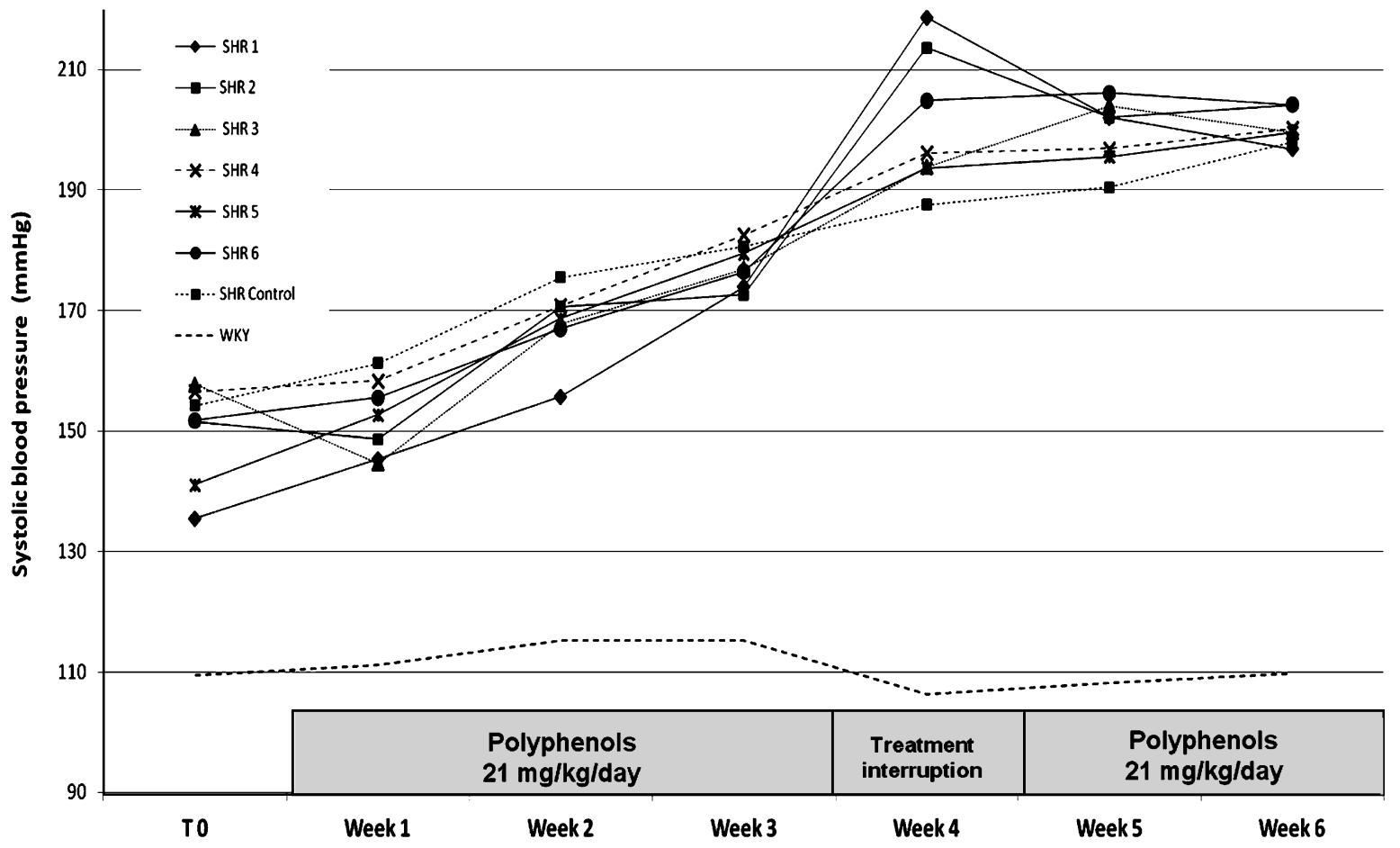

Fig. 2. Effect of polyphenolic extracts on the mean systolic blood pressure during the 6-week study.

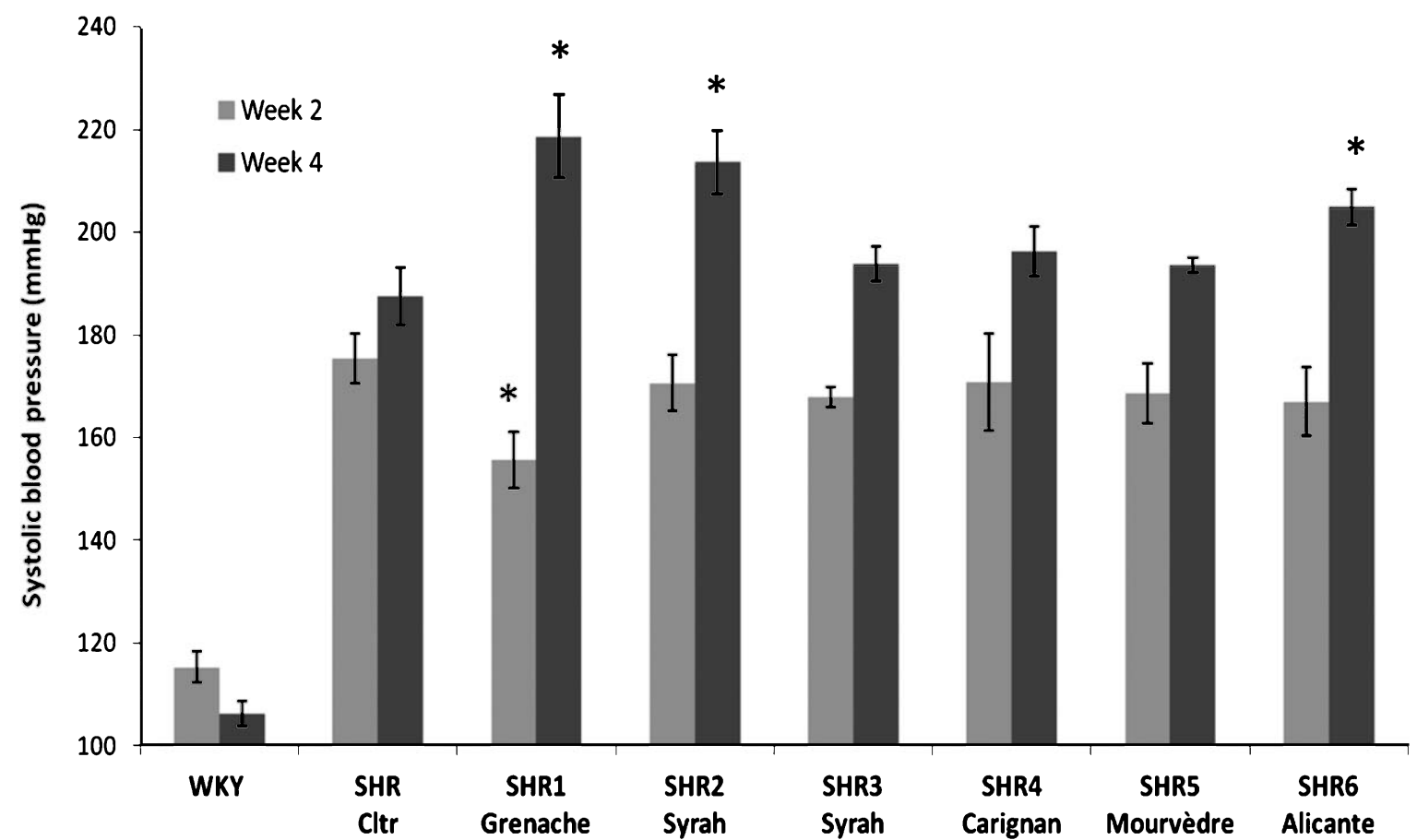

Fig. 3. Systolic blood pressure measured at week 2 (after 14 days of treatment with pomace extracts) and at week 4 (after 7 days of therapeutic interruption) $\left({ }^{*} p<0.05\right)$. 
Table 2

Phenolic composition in grape and pomace skin extracts

\begin{tabular}{|c|c|c|c|c|c|c|}
\hline & & TPC & Total tannins & Total antho & $\Sigma$ Monomers & $\Sigma$ Dimers \\
\hline \multirow[t]{2}{*}{$\mathrm{GRE}^{\mathrm{a}}$} & Grapes & $37.42 \pm 0.70$ & $59.52 \pm 5.16$ & $11.19 \pm 0.18$ & $1.57 \pm 0.01$ & $0.07 \pm 0.00$ \\
\hline & Pomaces & $17.14 \pm 0.35$ & $33.92 \pm 1.36$ & $1.55 \pm 0.12$ & $0.51 \pm 0.00$ & $0.07 \pm 0.00$ \\
\hline \multirow[t]{2}{*}{ GRE2 } & Grapes & $37.94 \pm 0.05$ & $63.80 \pm 0.71$ & $8.44 \pm 0.70$ & $3.19 \pm 0.00$ & $0.07 \pm 0.00$ \\
\hline & Pomaces & $19.54 \pm 1.03$ & $35.18 \pm 0.23$ & $3.24 \pm 0.03$ & $0.76 \pm 0.07$ & $0.08 \pm 0.00$ \\
\hline \multirow[t]{2}{*}{ SYR1 } & Grapes & $45.17 \pm 2.22$ & $73.01 \pm 6.02$ & $12.06 \pm 0.29$ & $1.84 \pm 0.00$ & $0.04 \pm 0.00$ \\
\hline & Pomaces & $24.32 \pm 0.00$ & $35.91 \pm 1.07$ & $4.94 \pm 0.09$ & $0.65 \pm 0.04$ & $0.15 \pm 0.01$ \\
\hline \multirow[t]{3}{*}{ SYR2 } & Grapes & $39.74 \pm 0.32$ & $66.83 \pm 3.30$ & $10.77 \pm 0.12$ & $2.48 \pm 0.11$ & $0.04 \pm 0.00$ \\
\hline & Pomaces & $20.77 \pm 0.19$ & $31.77 \pm 0.11$ & $5.02 \pm 0.11$ & $0.82 \pm 0.10$ & $0.04 \pm 0.00$ \\
\hline & Pomaces & $20.77 \pm 0.19$ & $31.77 \pm 0.11$ & $5.02 \pm 0.11$ & $0.82 \pm 0.10$ & $0.04 \pm 0.00$ \\
\hline \multirow[t]{2}{*}{ CAR } & Grapes & $44.91 \pm 0.08$ & $65.19 \pm 0.71$ & $15.17 \pm 0.00$ & $4.29 \pm 0.02$ & $0.11 \pm 0.01$ \\
\hline & Pomaces & $25.12 \pm 1.10$ & $46.15 \pm 0.30$ & $7.69 \pm 0.47$ & $0.67 \pm 0.00$ & $0.08 \pm 0.01$ \\
\hline \multirow[t]{2}{*}{ MOU } & Grapes & $41.27 \pm 1.60$ & $70.78 \pm 3.09$ & $11.84 \pm 0.29$ & $3.89 \pm 0.03$ & $0.12 \pm 0.00$ \\
\hline & Pomaces & $26.30 \pm 0.27$ & $47.28 \pm 1.34$ & $3.82 \pm 0.25$ & $0.52 \pm 0.03$ & $0.11 \pm 0.00$ \\
\hline \multirow[t]{2}{*}{$\mathrm{COU}$} & Grapes & $34.78 \pm 0.01$ & $61.26 \pm 1.06$ & $8.69 \pm 0.44$ & $3.56 \pm 0.00$ & $0.10 \pm 0.01$ \\
\hline & Pomaces & $20.50 \pm 0.18$ & $37.61 \pm 0.35$ & $1.98 \pm 0.02$ & $1.29 \pm 0.13$ & $0.16 \pm 0.00$ \\
\hline \multirow[t]{2}{*}{ ALI } & Grapes & $52.31 \pm 3.89$ & $85.76 \pm 8.35$ & $18.15 \pm 2.53$ & $8.69 \pm 0.05$ & $0.27 \pm 0.00$ \\
\hline & Pomaces & $31.59 \pm 1.72$ & $55.30 \pm 5.70$ & $9.97 \pm 0.82$ & $2.42 \pm 0.19$ & $0.12 \pm 0.01$ \\
\hline
\end{tabular}

${ }^{a}$ GRE1 and GRE2, Grenache; SYR1 and SYR2, Syrah; CAR, Carignan; MOU, Mourvèdre, COU, Counoise; ALI, Alicante. In units of mg/g DW skin. Data are expressed as the mean of triplicate \pm standard deviation. TPC, total phenol content; Total antho, total anthocyanins; S Monomers, sum of catechin and epicatechin; S Dimers, sum of B1, B2, B3 and B4.

Table 3

Anthocyanic composition in grape and pomace skin extracts

\begin{tabular}{|c|c|c|c|c|}
\hline & & $\Sigma$ Gly & $\Sigma$ Ace & $\Sigma$ Coum \\
\hline \multirow[t]{2}{*}{ GRE1 $^{a}$} & Grapes & $12.17 \pm 0.00$ & $0.61 \pm 0.01$ & $1.14 \pm 0.00$ \\
\hline & Pomaces & $2.58 \pm 0.01$ & $0.18 \pm 0.00$ & $0.37 \pm 0.00$ \\
\hline \multirow[t]{2}{*}{ GRE2 $^{\mathrm{a}}$} & Grapes & $6.39 \pm 0.01$ & $0.98 \pm 0.30$ & $0.74 \pm 0.01$ \\
\hline & Pomaces & $8.57 \pm 0.01$ & $0.19 \pm 0.00$ & $0.97 \pm 0.00$ \\
\hline \multirow[t]{2}{*}{ SYR $1^{\mathrm{a}}$} & Grapes & $10.38 \pm 0.20$ & $0.70 \pm 0.00$ & $1.97 \pm 0.00$ \\
\hline & Pomaces & $10.54 \pm 0.00$ & $0.22 \pm 0.00$ & $5.29 \pm 0.00$ \\
\hline \multirow[t]{2}{*}{$\mathrm{SYR}^{\mathrm{a}}$} & Grapes & $8.15 \pm 0.10$ & $0.63 \pm 0.00$ & $1.12 \pm 0.00$ \\
\hline & Pomaces & $8.46 \pm 0.00$ & $0.18 \pm 0.00$ & $1.15 \pm 0.10$ \\
\hline \multirow[t]{2}{*}{$\mathrm{CAR}^{\mathrm{a}}$} & Grapes & $14.55 \pm 0.01$ & $0.74 \pm 0.00$ & $3.11 \pm 0.05$ \\
\hline & Pomaces & $13.74 \pm 0.02$ & $0.18 \pm 0.00$ & $3.05 \pm 0.01$ \\
\hline \multirow[t]{2}{*}{$\mathrm{MOU}^{\mathrm{a}}$} & Grapes & $6.78 \pm 0.16$ & $2.81 \pm 0.03$ & $1.62 \pm 0.01$ \\
\hline & Pomaces & $6.23 \pm 0.00$ & $0.17 \pm 0.00$ & $0.67 \pm 0.01$ \\
\hline \multirow[t]{2}{*}{$\mathrm{COU}^{\mathrm{a}}$} & Grapes & $6.38 \pm 0.01$ & $0.73 \pm 0.011$ & $1.43 \pm 0.00$ \\
\hline & Pomaces & $3.28 \pm 0.05$ & $0.20 \pm 0.00$ & $0.60 \pm 0.00$ \\
\hline \multirow[t]{2}{*}{$\mathrm{ALI}^{\mathrm{a}}$} & Grapes & $17.40 \pm 0.12$ & $1.57 \pm 0.00$ & $2.38 \pm 0.01$ \\
\hline & Pomaces & $14.33 \pm 0.00$ & $0.20 \pm 0.01$ & $4.07 \pm 0.00$ \\
\hline
\end{tabular}

${ }^{a}$ GRE1 and GRE2, Grenache; SYR1 and SYR2, Syrah; CAR, Carignan; MOU, Mourvédre, COU, Counoise; ALI, Alicante. In units of mg/g DW seed or skin. Data are expressed as the mean of triplicate \pm standard deviation. $\Sigma$ gly, sum of monoglucoside anthocyanins; $\Sigma$ Ace, sum of petunidin-3-O-acetylmonoglucoside, peonidin-3- $O$-acetylmonoglucoside and malvidin-3-O-acetylmonoglucoside; $\Sigma$ Coum, sum of peonidin-3-(6- $O$-p-coumaroyl)monoglucoside and malvidin-3-(6- $O$-p-coumaroyl)monoglucoside.

monomers $(7.8 \mathrm{mg} / \mathrm{g}$ DW in 2010) while ALI was a source of an appreciable quantity of proanthocyanidins $(7.4 \mathrm{mg} / \mathrm{g}$ DW of monomers, $2.2 \mathrm{mg} / \mathrm{g}$ DW of dimers and $0.34 \mathrm{mg} / \mathrm{g}$ DW of trimer C1). Regarding their respective grape pomace, SYR1 and ALI retained a high concentration of monomers with up to $6.5 \mathrm{mg} / \mathrm{g}$ DW remaining in ALI. GRE1, COU and ALI were still relatively rich in dimers. Indeed, $90 \%$ of monomers and $55 \%$ of dimers remained in GRE1 seed pomace and the respective figures for ALI, were $88 \%$ and $62 \%$.

\subsubsection{Grape and pomace skin extracts}

As expected, grape skins contained a lower concentration of phenolic compounds than in seeds. The TPC ranged from $34.8 \mathrm{mg} \mathrm{GAE} / \mathrm{g} \mathrm{DW}$ in COU to $52.3 \mathrm{mg}$ 


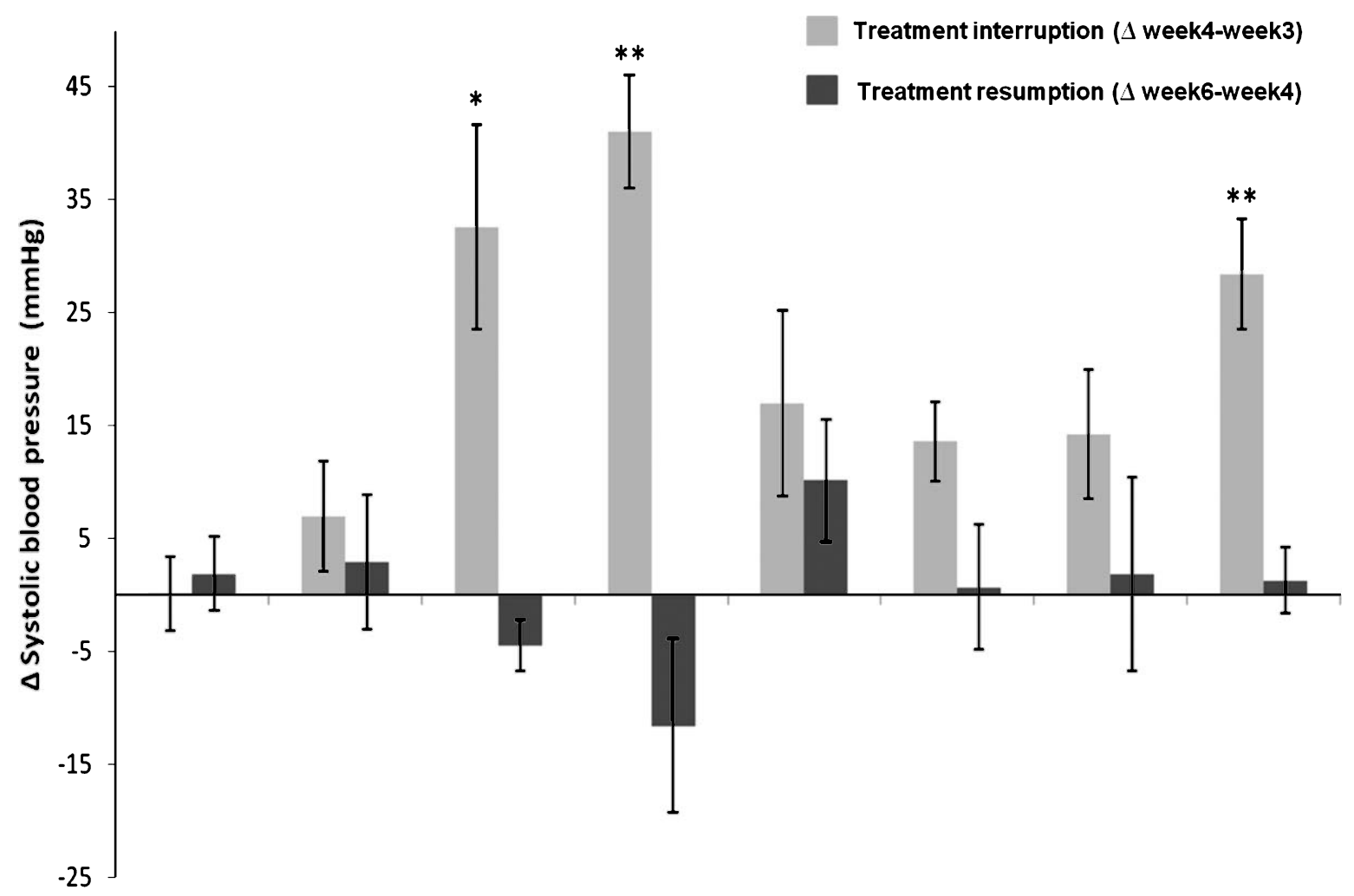

Fig. 4. Variations of systolic blood pressure during interruption and resumption period $(* p<0.05$, **p $p<0.01)$.

GAE/g DW in ALI (Table 2). The highest total tannin levels were found in ALI $(85.8 \mathrm{mg} / \mathrm{g}$ DW) and for total anthocyanins in SYR1, CAR, MOU and ALI. More than $45 \%$ of TPC and total tannins remained in the grape skin pomace of all the varieties. A different trend was observed concerning total anthocyanins especially for GRE1 (Fig. 1) where up to $80 \%$ of the initial amounts were extracted. Thus, anthocyanins appeared to be the most easily extractable phenolic compounds during vinification. Indeed, skins are more altered than seeds by the procedures such as pressing, crushing and maceration. During maceration, appreciable substantial quantities of anthocyanins are extracted into wine. As the level of alcohol increases during vinification, anthocyanins are solubilized and released in the acidic matrix [38].

Additional information was obtained when monomeric flavan-3-ols and oligomeric proanthocyanidins were analysed by HPLC. Grape varieties with the highest amounts of monomers and dimers in skins were the CAR, MOU and especially ALI which contained $8.7 \mathrm{mg} / \mathrm{g}$ DW of monomers and $0.3 \mathrm{mg} / \mathrm{g}$
DW of dimers. The vinification process removed more than $65 \%$ of the monomers and especially affected catechin levels (Table 2). Pomace from COU and ALI were the richest in monomeric and oligomeric proanthocyanidins.

The anthocyanin content of skin extracts was analysed by HPLC-UV and the profiles obtained were in good agreement with those obtained in previous studies with $V$. vinifera $L$. grapes [39, 40] and individual anthocyanin concentrations were well correlated with estimates of total anthocyanin content. For all varieties, malvidin-3- $O$-monoglucoside was the major anthocyanin and accounted for $40 \%$ to $55 \%$ of total anthocyanins depending on the variety. Grape skin extracts from ALI contained the highest quantities of glucoside-, acetyl- and $p$ coumaroyl-anthocyanins, $17.40,1.57$ and $2.38 \mathrm{mg} / \mathrm{g}$ DW, respectively (Table 3). Among "non-teinturier" varieties, SYR1 and CAR were particularly rich in glycosylated and $p$-coumaroylated anthocyanins while MOU was rich in acetylated anthocyanins. Appreciable amounts of anthocyanins remained in grape skin 


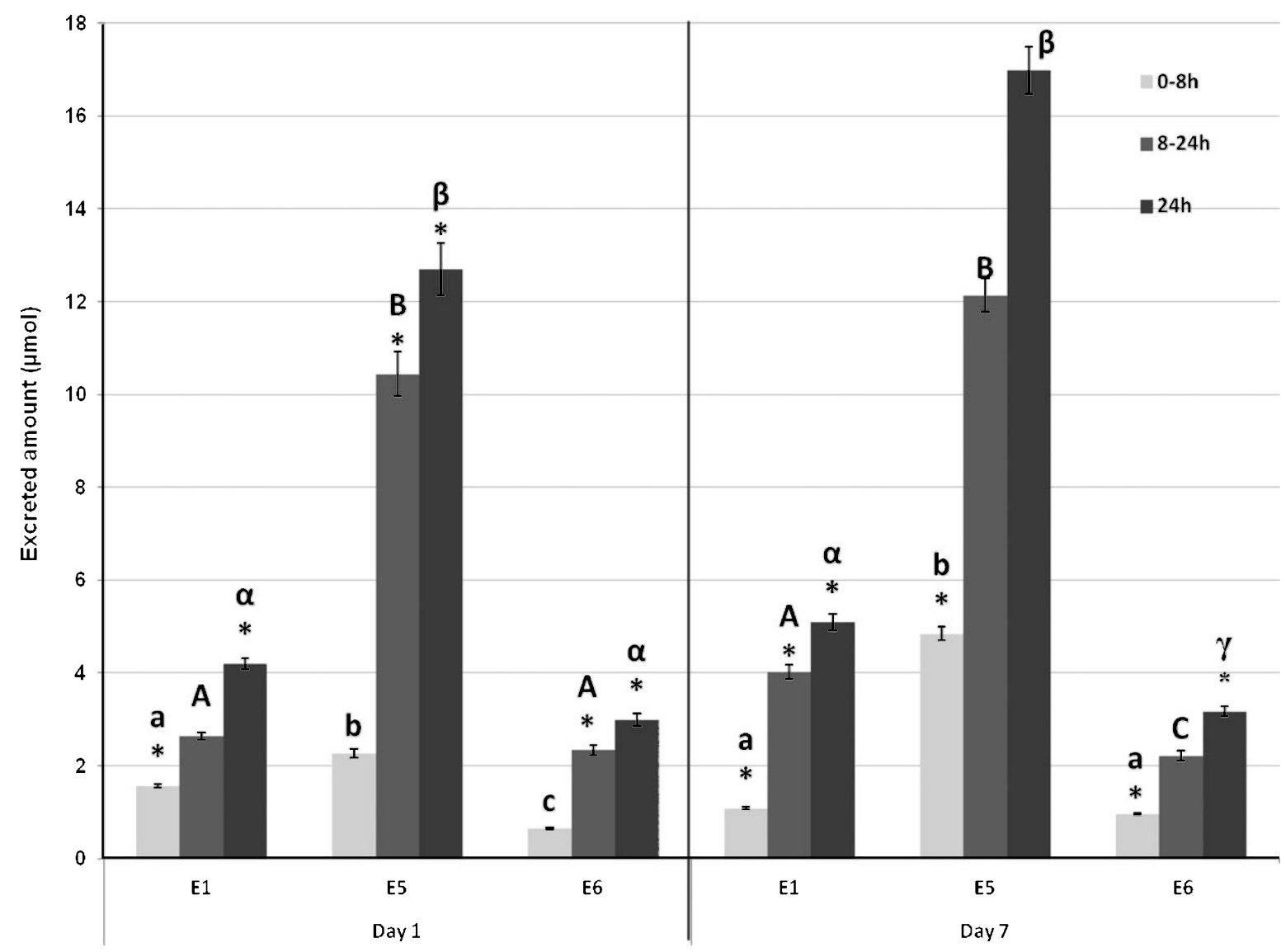

Fig. 5. Total significant urinary catabolites excreted at day 1 and day 7 after ingestion of grape pomace extracts (E1: Grenache seed pomace extract, E5: Mourvèdre skin pomace extract and E6: Alicante skin pomace extract). *Sum of catabolites that are excreted in significantly higher amounts compared to their respective control. a,A, $\alpha$; Anova was made to compare values obtain during 0-8h, 8-24 and 24h at day 1 and day 7. Same letters indicate no significant differences between the value $(p<0.05)$. Data are expressed as mean values in $\mu$ mol \pm Std.

pomace of SYR1, CAR and ALI, with up to $14.3 \mathrm{mg} / \mathrm{g}$ DW, $0.22 \mathrm{mg} / \mathrm{g}$ DW and $5.3 \mathrm{mg} / \mathrm{g}$ DW of glucoside, acetyl- and $p$-coumaroyl-anthocyanins, respectively, being retained. Skin pomace of GRE1 and COU contained the lowest levels of anthocyanins whereas CAR, GRE2, SYR and MOU retained high quantities of glucoside-, acetyl- and p-coumaroyl-anthocyanins.

The above data obtained on grape skins and pomace skins indicated that wine making process resulted in a relative increase $p$-coumaroyl derivatives and a decrease of the acetyl-anthocyanins. This phenomenon has also been observed in an earlier study which found that the relative content of $p$-coumaroyl derivatives of malvidin and peonidin was lower in wines than in fresh grape skins but higher in pomace [41]. Slow extraction rates of the $p$-coumaroyl anthocyanins from skins during vinification have been reported, explaining the presence of similar amounts of these anthocyanins in fresh grape skins and pomace skins [42].

\section{In vivo results}

Spontaneously hypertensive rats (SHR) selected for this study is frequently used to carry out studies on the antihypertensive effect of functional food ingredients. This strain represents nowadays the best experimental model for essential hypertension in humans and have shown its efficiency in many studies [43-48].

In order to evaluate the in vivo effect of grape pomace extracts and their potential effect on hypertension, rats were fed with different grape pomace extracts at a dose of $21 \mathrm{mg} / \mathrm{kg} /$ day, equivalent to a daily dose of 


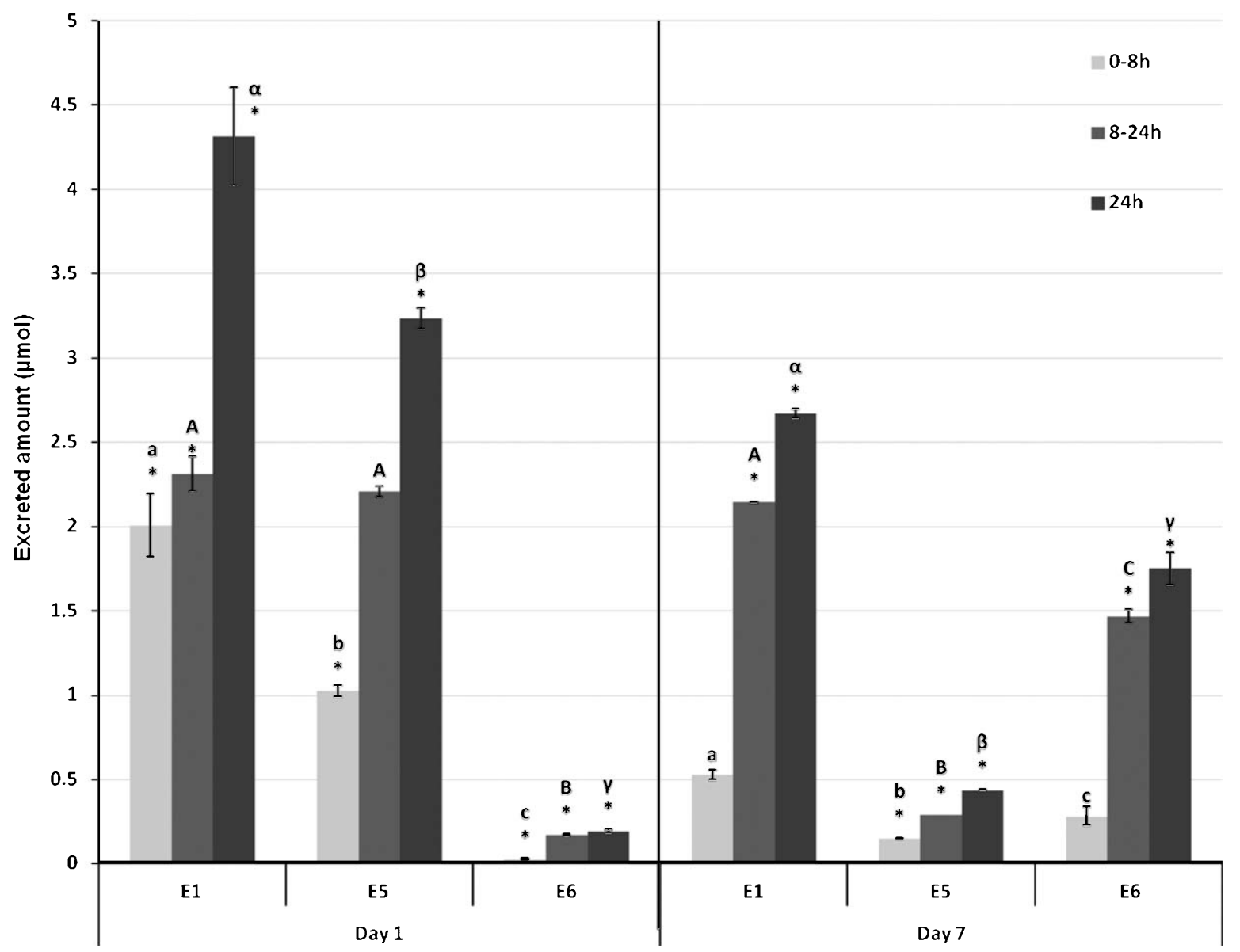

Fig. 6. Total significant faecal catabolites excreted at day 1 and day 7 after ingestion of grape pomace extracts (E1: Grenache seed pomace extract, E5: Mourvédre skin pomace extract and E6: Alicante skin pomace extract). ${ }^{*}$ Sum of catabolites that are excreted in significantly higher amounts compared to their respective control. a,A, $\alpha$; Anova was made to compare values obtain during 0-8 h, 8-24 and $24 \mathrm{~h}$ at day 1 and day 7 . Same letters indicate no significant differences between the value $(p<0.05)$. Data are expressed as mean values in $\mu \mathrm{mol} \pm \mathrm{Std}$.

$70 \mathrm{~kg}$ human consumption of $0.5 \mathrm{~L}$ of wine. Study was conducted during six weeks including three weeks of treatments, one week of treatment resumption followed again by two weeks of treatment.

Concerning the first experiment, as expected, the growth of WKY $(3.3 \pm 0.09 \mathrm{~g} /$ day $)$ were higher than those observed in SHR rats $(2.49 \pm 0.16 \mathrm{~g} /$ day $)$ without significative influence of grape pomace extracts on weight gain. The mean systolic blood pressure of SHR rats was comprised between $150 \mathrm{mmHg}$ at the beginning of the experiment and $190 \mathrm{mmHg}$ after five weeks (Fig. 2). Polyphenolic extracts gave to SHR rats have little effect on systolic blood pressure which increased gradually (except for the SHR 1 after 2 weeks of treatments) (Fig. 3). However, after three weeks, gavage intolerance were observed and caused difficult the administration of polyphenolic extracts, forcing the interruption of the treatment during one week. This treatment interruption was followed by an increase of the systolic blood pressure in SHR1 (Grenache seed pomace extract), SHR2 (Syrah seed pomace extract) and SHR6 (Alicante skin pomace extract) group compared to the SHR control group. This phenomenon can be intepretated as a « rebound effect » commonly observed with anti-hypertensive drugs and may reveal an antihypertensive effect of grape pomace extracts (Fig. 4). However, the treatment resumption at week 5 and 6 was not followed by a decrease of the systolic blood pressure nor another « rebound effect » during the re-interruption of the treatment (data not shown).

The previous experiment evidenced Grenache seed (E1) and Alicante skin (E6) extracts as having an anti- 
Table 4

GC-MS identification of phenolic acids detected in urine following ingestion of seed or skin grape pomace extracts

\begin{tabular}{|c|c|c|c|}
\hline Rt (min) & Compounds & Target ion $(\mathrm{m} / \mathrm{z})$ & Qualifier ion $(m / z)$ \\
\hline 6.19 & Benzoic acid & 179 & $105,135,77,147$ \\
\hline 6.72 & Pyrocatechol & 73 & 254,239 \\
\hline 9.73 & 3-Hydroxybenzoic acid & 267 & $73,147,193,223,282,253$ \\
\hline 10.03 & 3-(Phenyl) lactic acid & 193 & $14773,220,267,295$ \\
\hline 10.49 & 3'-Hydroxyphenylacetic acid & 73 & $164,147,296,281$ \\
\hline 10.91 & 4-Hydroxybenzoic acid & 267 & $223,193,73,282$ \\
\hline 11.14 & 4'-Hydroxyphenyl acetic acid & 73 & $179,164.252,281,296$ \\
\hline 12.98 & $3^{\prime}, 4^{\prime}$-Dimethoxyphenylacetic acid & 209 & $73,268,151,253$ \\
\hline 13.28 & 3-(3'-Hydroxyphenyl)propionic acid & 205 & $192,310,177,73$ \\
\hline 14.16 & $3^{\prime}, 4^{\prime}$-Dihydroxyphenylpropionic acid & 179 & $73,192,174,310$ \\
\hline 14.28 & 3-Methoxy-4-hydroxybenzoic acid & 297 & $267,312,73,223,253,282,126,193$ \\
\hline 14.46 & $4^{\prime}$-Hydroxy-3'-methoxyphenylacetic acid & 73 & $326,209,311,179,267,147$ \\
\hline 14.76 & $4^{\prime}$-Hydroxymandelic acid & 267 & $73,147,341$ \\
\hline 15.55 & Hippuric acid & 105 & 206,73 \\
\hline 18.65 & 3-(3'-Methoxy-4'-hydroxy)phenylpropionic acid & 209 & $340,73,192,79,310,325$ \\
\hline 20.41 & $p$-Coumaric acid & 219 & $293,308,73,249$ \\
\hline 21.91 & Gallic acid & 281 & $398,293,73$ \\
\hline 27.11 & Ferulic acid & 338 & $309,323,247,73,293$ \\
\hline 29.47 & Caffeic acid & 396 & $219,291,73,307,381$ \\
\hline 29.70 & $3^{\prime}$-Hydroxy hippuric acid & 294 & $73,193,147$ \\
\hline 33.37 & Sinapic acid & 193 & $294,73,147$ \\
\hline
\end{tabular}

Table 5

GC-MS identification of phenolic acids detected in faeces following ingestion of seed or skin grape pomace extracts

\begin{tabular}{lccc}
\hline Rt (min) & Compounds & Target ion $(\mathrm{m} / z)$ & Qualifier ion $(\mathrm{m} / z)$ \\
\hline 6.22 & Benzoic acid & 179 & $105,77,135,147,194$ \\
6.60 & Phenylacetic acid & 73 & $147,164,193,91$ \\
7.80 & $3^{\prime}$-Phenylpropionic acid & 104 & $75,147,207,179,222,91$ \\
10.09 & 3-(Phenyl)-lactic acid & 193 & $73,147,220,295$ \\
10.56 & 3'-Hydroxyphenylacetic acid & 73 & $147,164,281,296$ \\
10.88 & 4-Hydroxybenzoic acid & 267 & $147,223,193,282$ \\
11.21 & 4'-Hydroxyphenylacetic acid & 73 & $179,164,296,281,252,147$ \\
13.38 & 3-(3'-Hydroxyphenyl)propionic acid & 205 & $192,310,177,73$ \\
18.60 & 3-(3'-Methoxy-4'-hydroxy)phenylpropionic acid & 340 & $209,192,73,310.179,222$ \\
27.28 & Ferulic acid & 338 & $249,323,308,293,73,147$ \\
\hline
\end{tabular}

hypertensive potential. In a second experiment, for the study of bioavailability, these two extracts and Mourvédre skin extract (E5) were chosen. Urines and faeces at day 0 and day 7 were collected at $0-8 \mathrm{~h}$ and $8-24 \mathrm{~h}$ after ingestion of different grape pomace extracts. The phenolic acids of the urine and faecal samples were analysed quantitatively by GC-MS representing urinary and faecal excretion of these compounds in their unconjugated form. Only catabolites that are excreted in significantly higher amounts than the control were taken into account in order to exclude the background noise.

Concerning the urines, a total of 21 of phenolic acids were identified (Table 4). The great majority of the phe- nolic acids were excreted in 8-24 h urine after grape pomace extracts ingestion (Fig. 5). Total significant catabolite excreted values ranged from $2.33 \mu \mathrm{mol}$ in E6 to $10.43 \mu \mathrm{mol}$ in E5 and from $2.21 \mu \mathrm{mol}$ in E6 to $12.13 \mu \mathrm{mol}$ in E5 at day 1 and day 7 respectively. The maximum was observed in rats fed with E5 whether at day 1 or day 7 . For faeces, a total of 10 phenolic acids were identified (Table 5). The highest faecal excretion was detected in rat fed with the extract E1 with a maximum of $4.31 \mu \mathrm{mol}$ at day 1 and $2.67 \mu \mathrm{mol}$ at day 7 of total catabolite excreted over $24 \mathrm{~h}$ (Fig. 6). The lowest were obtained with E6 $(0.19 \mu \mathrm{mol})$ at day 1 and E5 $(0.44 \mu \mathrm{mol})$ at day 7 . Considering these results, especially those obtained in urines, a higher 
absorption of flavonoids was observed in rats fed with the Mourvèdre skin pomace extract (E5). Extract E1 (Grenache seed) and E6 (Alicante skin) seemed to be less absorbed despite an antihypertensive potential observed in the first experiment. At this stage, we can hypothesise that flavonoids in E1 and E6 compared to E5 might pass more easily the small intestine barrier and appear in the circulatory system predominantly as glucuronide, sulphate and methylated metabolites and join the bloodstream. A great majority in E5 might largely pass in the large intestine. Indeed, even after the absorption in small intestine, substantial quantities of flavonoids pass from the small to the large intestine and are subjected to the action of colonic microflora where most of them are broken down and yield a diversity of phenolic acids $[49,50]$. Colonic-derived catabolites can possibly be absorbed into the bloodstream again and passes through the body prior to excretion in urine.

For the meantime, any conclusions can be made. The analysis has to be completed with data obtained from LC-MS which allowed the identification of metabolites in the form of $O$-methylated, sulphated and glucuronidated in plasmas, urines and tissues. Information concerning absorption in the small intestine will then be provided and complete the bioavailability study.

\section{Conclusions}

This investigation screened the phenolic composition of by-products obtained after vinification of different Mediterranean grape varieties, in order to assess their potential for nutraceutical applications. Despite extraction during vinification, grape seed and skin pomace extracts contained appreciable amounts of flavan-3-ols and anthocyanins. The quantitative and qualitative distribution of polyphenols in grape pomaces showed significant differences through varieties. Seeds from Grenache (GRE1), Syrah (SYR1) and Alicante and skins from Syrah (SYR1), Carignan and Alicante were evidenced as the most interesting fractions because of their richest polyphenol content. The in vivo study also showed the efficiency of Grenache seed pomace and Alicante skin pomace extracts to regulate blood pressure which was illustrated by a rebound effect. In this work, the degradation and subsequent excretion of grape pomace polyphenols knows to enter the large intestine after ingestion of grape seed/skin pomace extracts were studied by GC-MS analysis. These results should be completed with data obtain from LC-MS in order to get an overall picture of the bioavailability of each extracts. These first results evidenced grape pomace extracts as useful by-products which could be used as a natural source of polyphenols and antioxidants for nutraceutical formulations.

\section{References}

[1] Mennen LI, Sapinho D, et al. Consumption of foods rich in flavonoids is related to a decreased cardiovascular risk in apparently healthy french women. The Journal of Nutrition 2004;134(4):923-6.

[2] He FJ, Nowson CA, et al. Increased consumption of fruit and vegetables is related to a reduced risk of coronary heart disease: Meta-analysis of cohort studies. J Hum Hypertens 2007;21(9):717-28.

[3] Chong MFF, MacDonald R, et al. Fruit polyphenols and CVD risk: A review of human intervention studies. British Journal of Nutrition 2010;104(Suppl. 3):S28-39.

[4] Monagas M, Bartolomé B, et al. Updated knowledge about the presence of phenolic compounds in wine. Critical Reviews in Food Science and Nutrition 2005;45(2):85-118.

[5] Teissedre PL, Frankel EN, et al. Inhibition of in vitro human LDL-oxidation by phenolic antioxidants from grapes and wines. Journal of the Science of Food and Agriculture 1996;70(1):55-61.

[6] Natella F, Ghiselli A, et al. Red wine mitigates the postprandial increase of LDL susceptibility to oxidation. Free Radical Biology and Medicine 2001;30(9):1036-44.

[7] Gorelik S, Ligumsky M, et al. A novel function of red wine polyphenols in humans: Prevention of absorption of cytotoxic lipid peroxidation products. Faseb Journal 2008;22(1): 41-6.

[8] Bagchi D, Bagchi M, et al. Free radicals and grape seed proanthocyanidin extract: Importance in human health and disease prevention. Toxicology 2000;148(2-3):187-97.

[9] Delmas D, Jannin B, et al. Resveratrol: Preventing properties against vascular alterations and ageing. Molecular Nutrition \& Food Research 2005;49(5):377-95.

[10] Castilla P, Echarri R, et al. Concentrated red grape juice exerts antioxidant, hypolipidemic, and antiinflammatory effects in both hemodialysis patients and healthy subjects. The American Journal of Clinical Nutrition 2006;84(1):252-62.

[11] Stein JH, Keevil JG, et al. Purple grape juice improves endothelial function and reduces the susceptibility of LDL cholesterol to oxidation in patients with coronary artery disease. Circulation 1999;100(10):1050-5.

[12] Sano A, Uchida R, et al. Beneficial effects of grape seed extract on malondialdehyde-modified LDL. Journal of Nutritional Science and Vitaminology 2007;53(2):174-82.

[13] Shanmuganayagam D, Beahm MR, et al. Grape seed and grape skin extracts elicit a greater antiplatelet effect when used in combination than when used individually in dogs and humans. The Journal of Nutrition 2002;132(12):3592-8.

[14] Arts IC, Hollman PC. Polyphenols and disease risk in epidemiologic studies. The American Journal of Clinical Nutrition 2005;81(1):317S-25S. 
[15] Halliwell B. Free radicals, antioxidants, and human disease: Curiosity, cause, or consequence? The Lancet 1994;344(8924): 721-4.

[16] Dröge W. Free radicals in the physiological control of cell function. Physiological Reviews 2002;82(1):47-95.

[17] Fitzpatrick DF, Hirschfield SL, et al. Endothelium-dependent vasorelaxing activity of wine and other grape products. American Journal of Physiology - Heart and Circulatory Physiology 1993;265(2 34-2):H774-8.

[18] Andriambeloson E, Kleschyov AL, et al. Nitric oxide production and endothelium-dependent vasorelaxation induced by wine polyphenols in rat aorta. British Journal of Pharmacology 1997;120(6):1053-8.

[19] Soares de Moura R, Viana FSC, et al. Antihypertensive, vasodilator and antioxidant effects of a vinifera grape skin extract. Journal of Pharmacy and Pharmacology 2002;54(11): 1515-20.

[20] Kwan C-Y, Zhang W-B, et al. Endothelium-dependent vascular relaxation induced by Eucommia ulmoides Oliv. bark extract is mediated by NO and EDHF in small vessels. NaunynSchmiedeberg's Archives of Pharmacology 2004;369(2): 206-11.

[21] Ndiaye M, Chataigneau $\mathrm{T}$, et al. Red wine polyphenols induce EDHF-mediated relaxations in porcine coronary arteries through the redox-sensitive activation of the PI3-kinase/Akt pathway. British Journal of Pharmacology 2004;142(7):11316.

[22] Mizugaki M, Ishizawa F, et al. Epigallocatechin gallate increase the prostacyclin production of bovine aortic endothelial cells $\{$. Prostaglandins \& Other Lipid Mediators 2000;62(2):157-64.

[23] Aldini G, Carini M, et al. Procyanidins from grape seeds protect endothelial cells from peroxynitrite damage and enhance endothelium-dependent relaxation in human artery: New evidences for cardio-protection. Life Sciences 2003;73(22): 2883-98.

[24] Corder R, Douthwaite JA, et al. Health: Endothelin-1 synthesis reduced by red wine. Nature 2001;414(6866):863-4.

[25] Laufenberg G, Kunz B, et al. Transformation of vegetable waste into value added products: (A) the upgrading concept; (B) practical implementations. Bioresource Technology 2003;87(2):167-98.

[26] Llobera A, Cañellas J. Dietary fibre content and antioxidant activity of Manto Negro red grape (Vitis vinifera): Pomace and stem. Food Chemistry 2007;101(2):659-66.

[27] Kammerer D, Claus A, et al. Polyphenol screening of pomace from red and white grape varieties (Vitis vinifera L.) by HPLCDAD-MS/MS. Journal of Agricultural and Food Chemistry 2004;52(14):4360-7.

[28] Ruberto G, Renda A, et al. Polyphenol constituents and antioxidant activity of grape pomace extracts from five Sicilian red grape cultivars. Food Chemistry 2007;100(1):203-10.

[29] Alonso ÁM, Guillén DA, et al. Determination of antioxidant activity of wine byproducts and its correlation with polyphenolic content. Journal of Agricultural and Food Chemistry 2002;50(21):5832-6.

[30] Negro C, Tommasi L, et al. Phenolic compounds and antioxidant activity from red grape marc extracts. Bioresource Technology 2003;87(1):41-4.
[31] Louli V, Ragoussis N, et al. Recovery of phenolic antioxidants from wine industry by-products. Bioresource Technology 2004;92(2):201-8.

[32] Lafka TI, Sinanoglou V, et al. On the extraction and antioxidant activity of phenolic compounds from winery wastes. Food Chemistry 2007;104(3):1206-14.

[33] Xu Y, Simon JE, et al. Survey of polyphenol constituents in grapes and grape-derived products. Journal of Agricultural and Food Chemistry 2011;59(19):10586-93.

[34] FAO (2010). Statistical databases. (electronical resource): France : FAO.

[35] Buffin JC. Educvin: Votre talent de la dégustation, Oenoplurimédia. 2000.

[36] Silva MA, Ky I, et al. Rapid and simple method for the quantification of flavan-3-ols in wine. European Food Research and Technology 2011;1-5.

[37] Buñag RD. Validation in awake rats of a tail-cuff method for measuring systolic pressure. Journal of Applied Physiology 1973;34(2):279-82.

[38] Ribereau-Gayon P, Glories Y, et al. Phenolic Compounds, 141-203, Handbook of Enology. The chemistry of wine. Stabilization and treatments. John Wiley \& Sons, Ltd, 2006.

[39] Romero-Cascales I, Ortega-Regules A, et al. Differences in Anthocyanin Extractability from Grapes to Wines According to Variety. American Journal of Enology and Viticulture 2005; 56(3):212-9.

[40] Liang Z, Wu B, et al. Anthocyanin composition and content in grape berry skin in Vitis germplasm. Food Chemistry 2008;111(4):837-44.

[41] García-Beneytez E, Revilla E, et al. Anthocyanin pattern of several red grape cultivars and wines made from them. European Food Research and Technology 2002;215(1):32-7.

[42] Fournand D, Vicens A, et al. Accumulation and extractability of grape skin tannins and anthocyanins at different advanced physiological stages. Journal of Agricultural and Food Chemistry 2006;54(19):7331-8.

[43] Wada T, Sanada T, et al. Combined effects of the angiotensin II antagonist candesartan cilexetil (TCV-116) and other classes of antihypertensive drugs in spontaneously hypertensive rats. Hypertens Research 1996;19(4):247-54.

[44] Bravo L, Herrera MD, et al. Cardiovascular effects of lovastatin in normotensive and spontaneously hypertensive rats. General Pharmacology 1998;30(3):331-6.

[45] Al-Awwadi NA, Bornet A, et al. Red wine polyphenols alone or in association with ethanol prevent hypertension, cardiac hypertrophy, and production of reactive oxygen species in the insulin-resistant fructose-fed rat. Journal of Agricultural and Food Chemistry 2004;52(18):5593-7.

[46] Quiñones M, Sánchez D, et al. Long-term intake of CocoanOX attenuates the development of hypertension in spontaneously hypertensive rats. Food Chemistry 2010;122(4):1013-9.

[47] Mukai Y, Sato S. Polyphenol-containing azuki bean (Vigna angularis) seed coats attenuate vascular oxidative stress and inflammation in spontaneously hypertensive rats. The Journal of Nutritional Biochemistry 2011;22(1):16-21.

[48] Yang N-C, Jhou K-Y, et al. Antihypertensive effect of mulberry leaf aqueous extract containing $\gamma$-aminobutyric acid in spontaneously hypertensive rats. Food Chemistry 2012; 132(4):1796-801. 
[49] Selma MaV, Espín JC, et al. Interaction between Phenolics and Gut Microbiota: Role in Human Health. Journal of Agricultural and Food Chemistry 2009;57(15):6485-501.
[50] Crozier A, Del Rio D, et al. Bioavailability of dietary flavonoids and phenolic compounds. Molecular Aspects of Medicine 2010;31(6):446-67. 